\title{
Tempos de covid-19: as doenças têm história, os trabalhadores também
}

\author{
Gabriela dos Reis Sampaio* \\ Ricardo dos Santos Batista*
}

$\mathrm{V}$ ivemos um presente distópico, de pandemia e mudança repentina de hábitos, paradigmas, maneiras de compreender a realidade e lidar com suas consequências em nossa vida cotidiana. Uma realidade que foi pincelada, de maneira mais ou menos próxima ao que vivenciamos, por autores de ficção do século passado. O historiador Sidney Chalhoub se referiu ao momento que enfrentamos neste ano de 2020, com a pandemia da covid-19, como uma distopia neoliberal. Uma doença desconhecida, um vírus novo, e em poucos meses o mundo inteiro parou - e se trancou em casa. Ao menos quem pode. A pandemia obrigou os mercados a reduzir sua atividade, forçou o isolamento, encerrando viagens locais e internacionais, fechando fronteiras, na contramão da defesa exagerada do consumo e das propostas de um neoliberalismo privatista de extrema direita que se instalou em grande parte do mundo neste começo de século. A tão ovacionada globalização que, como descreveu Frederick Cooper, é sempre invocada para incentivar os países ricos a diminuir o Estado social e os países pobres a reduzir as despesas sociais, sofreu um forte abalo com a covid-19. ${ }^{1}$ Mais do que nunca, ficou explícita a importância de um sistema de saúde público e eficiente, de um Estado consistente que centralize a organização de todas as forças possíveis para salvar vidas.

Por outro lado, a pandemia evidenciou ainda mais as desigualdades e injustiças sociais. Se a doença atinge igualmente a todos, as maneiras de lidar com a ameaça à vida e com seus efeitos variam enormemente. A epidemia alterou as condições de vida e de trabalho de

\footnotetext{
* Doutora em História Social pela Universidade Estadual de Campinas (Unicamp). Professora do Departamento de História e do Programa de Pós-Graduação em História da Universidade Federal da Bahia (UFBA). ORCID: https://orcid.org/0000-0003-1942-9096. E-mail: grsampaio@hotmail.com.

** Doutor em História Social pela Universidade Federal da Bahia (UFBA). Professor da graduação em História e do Programa de Pós-Graduação em História da Universidade do Estado da Bahia (UNEB). ORCID: https:// orcid.org/0000-0002-7959-5929. E-mail: kadobatista@hotmail.com.

1 COOPER, Frederick. História da África: capitalismo, modernidade e globalização. Lisboa: Edições 70, 2016, p. 177, apud SILVA, Fernando Teixeira. Reforma trabalhista: emprego, tempo e história. In: SPERANZA, Clarice Gontarski (org.). História do trabalho: entre debates, caminhos e encruzilhadas. Jundiaí: Paco Editorial, 2019. p. 18.
} 
milhões de pessoas pelo mundo, causando aumento do desemprego e aumentando ainda mais a precarização dos trabalhadores e a pobreza. No Brasil, onde o número de mortes chega a 140 mil no momento em que escrevemos esta apresentação, os efeitos devastadores da pandemia atingem de maneira dramática os mais pobres e mais frágeis. Os trabalhadores precarizados, em sua maioria negros, mais expostos em função da impossibilidade de ficar em casa - ou da dificuldade em se isolar quando moram em casas pequenas, compartilhadas por vários membros da família - se tornaram as vítimas principais da doença.

A tragédia, que poderia ter sido bem menor se medidas relativamente simples fossem tomadas, nos faz pensar sobre as injustiças históricas cometidas no país em relação aos trabalhadores. Infelizmente, não é novidade para nós, historiadores, verificar o impacto devastador de uma epidemia nas sociedades. O contexto nos provocou e nos levou à organização deste dossiê, com artigos específicos sobre o tema das doenças, e das diferentes formas de lidar com elas pelos mais variados sujeitos sociais, médicos, autoridades, líderes políticos e religiosos. Debates em torno dos cuidados, quarentenas, isolamento e seus efeitos devastadores sobre a economia circularam de maneira virulenta em períodos não tão distantes de nós, quando grassavam no país epidemias de febre amarela, cólera, varíola, entre outras doenças contagiosas. Os conflitos entre prescrições médicas, deliberações das autoridades e atitudes da população a elas sujeitas sempre surgiram, e trabalhadores muitas vezes buscaram suas próprias maneiras de lidar com as calamidades e sobreviver ao caos. As epidemias de febre amarela, cólera e varíola, bem como a famosa revolta popular ocorrida contra a vacina no Rio de Janeiro em 1904, são comentadas por Sidney Chalhoub na entrevista que abre este dossiê. O historiador, cujo trabalho é referência nos estudos sobre escravidão e também sobre epidemias, racismo e literatura, faz uma reflexão sobre o momento atual, levando-nos a um passeio pelo tema em outras conjunturas e nos convidando a pensar sobre vários aspectos envolvidos na questão das epidemias, como o racismo e a ciência.

Há um século, a chamada gripe espanhola devastava milhões de pessoas pelo mundo. Um vírus novo contagiava e ceifava vidas rapidamente, espalhando o terror e evidenciando os limites da ciência e dos líderes políticos em limitar o contágio, tratar os doentes e controlar as mortes. Neste dossiê, uma seção inteira - "Mundos do trabalho e a gripe 'espanhola' na Ibero-américa" - é dedicada à gripe, originada nos EUA, mas depois apelidada de "espanhola". São cinco artigos que tratam da doença em diferentes cidades e países. María-Isabel Porras-Gallo trata da gripe na Espanha, dando destaque às transformações que a epidemia gerou no ambiente de trabalho de profissionais de saúde como médicos, farmacêuticos e veterinários. Em seguida, Christiane Maria Cruz de Souza apresenta um minucioso estudo sobre a gripe espanhola na Bahia, destacando a situação de trabalhadores mais pobres e miseráveis da cidade de Salvador, em diferentes bairros. Alexandra Patrícia Esteves e Silvia Pinto vem em seguida fazendo um rico panorama do surto de gripe espanhola em Portugal, lá chamada de 
gripe pneumônica. O surto da gripe na Argentina nos é apresentado por Ádrian Carbonetti e María Dolores Rivero, que analisam os impactos da epidemia na economia argentina e as consequências da crise econômica gerada pela doença nas dinâmicas de trabalho e nas condições de vida de diferentes trabalhadores em Buenos Aires. Encerrando o bloco sobre a gripe espanhola e indo além dela, Liane Maria Bertucci discute as moradias operárias no contexto de três surtos epidêmicos na cidade de São Paulo: peste bubônica, varíola e gripe espanhola. A autora mostra que a ciência médica embasou críticas sociais e ao governo e divulgou, para os trabalhadores, um ideal de casa salubre e a importância das práticas higiênicas para a manutenção da saúde em períodos epidêmicos.

Para além dos contextos de epidemias, porém, há uma vasta tradição historiográfica de estudos relacionados às doenças e curas, pensando na atuação dos médicos e nas variadas experiências de pacientes, seus modos de crer, de lidar com as situações de desespero e as ameaças causadas pelas doenças. Os artigos selecionados, se tratam do tema das doenças, também dialogam com a tradição da História Social, privilegiando a visão dos trabalhadores e as condições enfrentadas em diferentes situações limite que vivenciaram. Causadas muitas vezes pelas precárias condições de vida e de trabalho, as reflexões sobre saúde e doença se entrelaçam com preocupações da História do Trabalho, levando em conta relações laborais, lutas por condições mínimas para se trabalhar e viver, experiências de organização, resistência e luta por existir na lógica perversa do capital.

Há muito os historiadores vêm estudando as doenças e seus impactos nas sociedades ao longo do tempo. As doenças têm história - e, como mostrou o historiador Jaques Le Goff nos anos 1980, trata-se de uma história dramática, que revela, na longa duração, a tragédia dos sintomas e de sentimentos de culpabilidade individual e coletiva, no caso de epidemias. Para além de uma mera "história superficial dos progressos científicos e tecnológicos", as doenças também pertencem, afirma Le Goff, à história de saberes, práticas, representações, mentalidades. Uma história que trata tanto dos saberes médicos quanto de crenças em magias, orações, ervas e que tais. ${ }^{2}$

Já vai longe a época em que se pensava o tema apenas do ponto de vista de um suposto poder onipresente da medicina, entendida como entidade homogênea e absoluta, ignorando os conflitos no interior das corporações médicas e mesmo dos médicos com o poder público. Também ficaram para trás noções de que, por meio do Estado, toda a sociedade seria medicalizada, sem reação ou sem que outras formas de entender e lidar com saúde e doença, bem como formas específicas de crença, mantivessem sua força e presença entre os mais variados e impacientes "pacientes". ${ }^{3}$ Desde ao menos os anos 1990, no Brasil, reflexões embasadas em pesquisas sólidas e diversificadas vêm consolidando todo um campo

2 LE GOFF, Jaques (org.). As doenças têm história. Lisboa: Terramar, 1985. p. 7-8.

3 Alguns trabalhos pioneiros na área de História da Medicina, se trouxeram contribuições muito importantes para a temática, incorreram em generalizações que, há bastante tempo, foram questionadas e superadas pelos historiadores. Sobre este debate, ver: CHALHOUB, Sidney et al. (org.). Artes e ofícios de curar no Brasil: capítulos de história social. Campinas: Editora da Unicamp, 2003. 
historiográfico, e os vários autores aqui presentes são parte deste movimento. Há também, neste volume, autores de fora do Brasil, dialogando diretamente com o tema proposto.

Desse modo, o esforço deste dossiê da Revista Mundos do Trabalho foi buscar a intersecção dessas áreas, já bastante consolidadas com pesquisa e reflexão teórica na historiografia nacional e internacional - História da Medicina e História do Trabalho -, pensando nas relações entre saúde e doença, bem como as formas de lidar com essas experiências, e as tradições de luta e resistência dos trabalhadores para lidar com o que se tentava impor a eles. Assim, as partes seguintes do volume tratam de várias doenças e artes de curar ligadas a diferentes mundos do trabalho.

A seção que segue a primeira, "Mundos do trabalho, doenças, escravidão e artes de curar", inicia-se com um trabalho de lamara Viana, Flávio Gomes e Tânia Salgado Pimenta sobre as enfermidades que acometiam os africanos em áreas cafeeiras no sudeste do Brasil, e o que diziam os médicos a seu respeito. Os autores relacionam as doenças com as péssimas condições de trabalho a que eram submetidos os escravizados, trazendo um excelente panorama da historiografia sobre o tema das doenças comuns entre os africanos, bem como da escravidão no sudeste cafeeiro. Em seguida, Paulo Roberto Staudt Moreira e Nikelen Witter analisam o ofício das parteiras, destacando sua importância social, as disputas por clientela e as sociabilidades femininas que giravam em torno deste exercício profissional. Por meio do estudo de processos criminais, tratam de casos de mulheres, parteiras e parturientes, discutindo questões ligadas ao trabalho doméstico, universo de pertencimento das parteiras estudadas. Já Alan Costa Cerqueira e Maihara Raianne Marques Vitória apresentam trajetórias de amas e criadeiras que prestavam serviço para a Santa Casa de Misericórdia da Bahia nas últimas décadas do século XIX, mostrando o quanto essa profissão era buscada, e as diversas controvérsias envolvidas no campo médico e intelectual sobre amamentação e cuidados com as crianças. $O$ artigo discute questões como a saúde dos bebês e das famílias que se utilizavam das amas, bem como as dificuldades enfrentadas por estas trabalhadoras e a alta mortalidade e desaparecimento de crianças do asilo, pelo que as amas também eram frequentemente responsabilizadas. Para fechar a seção sobre artes de curar, Rafael Rosa da Rocha traz para o debate casos de curadores brancos e negros em um mundo racializado e racista, no início do século XX, discutindo a questão da liberdade profissional em medicina nos anos iniciais da República, no contexto da elaboração do novo Código Penal e de uma nova constituição. Apesar de não sofrerem as mesmas restrições que os agentes de cura negros, os curadores brancos também enfrentavam restrições, analisadas em detalhe, revelando problemas jurídicos e políticos do momento e também questões de classe e raça.

$\mathrm{Na}$ seção seguinte, "Mundos do trabalho, políticas internacionais e profissões em saúde", Ricardo dos Santos Batista analisa a criação e o papel desempenhado pelo Serviço de Higiene Industrial da Bahia, entre 1925 e 1930, articulando questões locais, nacionais 
e internacionais na Reforma Sanitária brasileira da década de 1920. O autor identifica as doenças que afligiam os operários, sua organização no que dizia respeito à saúde, e as ações do Estado, que passou a defender a higiene nos locais de trabalho. O artigo de Luiz Otávio Ferreira vem em seguida apresentando as "guardiãs da saúde", no qual descreve representações e características socioculturais das mulheres que trabalhavam como enfermeiras em domicílios, hospitais e asilos na cidade do Rio de Janeiro no final do século XIX e início do século XX. A partir da análise de anúncios de oferta e de procura de serviços de enfermagem publicados entre 1880 e 1910 no Jornal do Commercio, o autor faz um diálogo com a bibliografia especializada e apresenta conclusões que cruzam questões de gênero, raça e classe. Ao final deste bloco, Pablo Maddalena analisa as continuidades e rupturas que o surgimento da Organização Internacional do Trabalho acarretou no tratamento dos riscos ocupacionais na Argentina nas duas décadas posteriores a 1915, quando foi promulgada no país uma lei sobre acidentes de trabalhos e doenças ocupacionais. $\mathrm{O}$ autor discute como as recomendações da instituição internacional moldaram a gestão dos acidentes de trabalho na Argentina, sugerindo que a OIT promoveu um conjunto de políticas preventivas de redução de riscos ocupacionais que teve impacto direto, ainda que com certa letargia, na regulamentação da lei argentina de acidentes de trabalho de 1915.

Os artigos da última seção, "Mundos do trabalho, doenças mentais e outras enfermidades", tratam de doenças específicas ligadas a diferentes trabalhadores. Em primeiro lugar, doenças que atingiam os mineradores de carvão no sul do Brasil, discutidas por Bruno Mandelli. O autor busca refletir sobre as condições do trabalho ligado à exploração do carvão e o surgimento da medicina do trabalho. Em seguida, dois textos exploram o universo das doenças mentais. Cláudio Bertolli Filho detalha o caso de um assassino, réu confesso, diagnosticado como louco e degenerado. O caso é usado para discutir o quanto havia de racismo na determinação - e tratamento - de doenças mentais, especialmente em se tratando de trabalhadores negros. Já Anna Beatriz de Sá Almeida e Ana Carolina de Azevedo Guedes descrevem histórias de homens internados na Colônia Juliano Moreira, hospital psiquiátrico do Rio de Janeiro, internados por indícios de doenças mentais relacionadas com o trabalho. Analisando prontuários dos internos durante o governo Vargas, as autoras se propõem a discutir como trabalho e trabalhador se tornam alvos de políticas públicas que buscavam a construção de um determinado projeto de nação, na qual determinadas ideias sobre trabalho e família eram centrais. Encerramos o bloco e o dossiê com a contribuição de André Mota, que discute doenças ligadas ao "progresso", isto é, relacionadas ao crescimento e desenvolvimento de cidades, usando o caso de São Paulo no começo do século XX para discutir a tuberculose e outras doenças cardiorrespiratórias ligadas aos trabalhadores.

O dossiê apresentado é, como se nota a partir desta introdução, riquíssimo, tanto em termos de temáticas surgidas quanto em relação à diversidade de autores, fontes e abordagens propostas. Os organizadores, tentando não se contaminar com tantos males físicos e mentais 
apresentados pelos autores, foram contagiados, na experiência de construir esse volume, pelo entusiasmo das análises e pela alta qualidade deste impressionante volume de história das doenças dos trabalhadores. Esperamos que os leitores também apanhem esses bons ventos. Saúde e longa vida a todos nós! 